\title{
GAMBARAN PERAN ORANG TUA DALAM MELINDUNGI ANAK USIA SEKOLAH DARI TINDAKAN PELECEHAN SEKSUAL DI SDN SANANWETAN 02 UPTD PENDIDIKAN KECAMATAN SANANWETAN KOTA BLITAR (Overview Parent Role in Protecting Children School Of Sexual Harassment in Action SDN Sananwetan 02 UPTD Education District Sananwetan City blitar)
}

\author{
Ryan Budianto \\ Praktisi Keperawatan \\ Email: ryan_budianto123@yahoo.com
}

\begin{abstract}
Children sex abuse is an immoral act done to the children under age such as school children. Parents role in protecting school children from sex abuse are by supervising, giving advise, providing early religious education, becoming a good role model, and creating a conducive atmosphere in family. The aim of the research was to describe parents role in protecting school children from sex abuse. The research design was a descriptive approach. The population was 578 parents of students in SDN Sanawetan 02 Blitar city. The sample was 58 parents taken by quota sampling. The data collection was done by door to door on July 6 - August 14, 2015. The result showed that 69\% (40 parents) less involved, 28\% (26 parents) fair involved, and 3\% (2 parents) actively involved. Factors affecting less involved parents was culture, education, and job. The role of Less involved parents showed by less interaction with the school, didn't give information on sex abuse, didn't accustom child to be extrovert, and avoid fighting in front of children. Increasing parents concern to children could decrease sex abuse of school children case.
\end{abstract}

Keywords: Parents Role, sexual harassment

\begin{abstract}
Abstrak: Pelecehan seksual pada anak di bawah umur adalah suatu tindakan asusila yang dilakukan pada anak yang belum cukup umur misalnya anak usia sekolah. Peran orang tua dalam melindungi anak usia sekolah dari tindakan pelecehan seksual yaitu mengawasi, menasehati, memberikan pendidikan agama sejak dini, menjadi figur yang dikagumi anak, dan menciptakan suasana yang kondusif dalam keluarga. Tujuan penelitian adalah untuk menggambarkan peran orang tua dalam melindungi anak usia sekolah dari tindakan pelecehan seksual. Desain penelitian yang digunakan ialah deskriptif. Populasi adalah orang tua yang memiliki anak bersekolah di SDN Sanawetan 02 Kota Blitar berjumlah 578. Besar sampel yang ditentukan ialah 58 orang tua dengan tehnik quota sampling. Pengumpulan data dengan door to door. Waktu pengambilan data 6 Juli-14 Agustus 2015. Hasil penelitian 69\% (40 orang tua) kurang berperan, 28\% ( 26 orang tua) cukup berperan, dan $3 \%$ ( 2 orang tua) sangat berperan. Faktor yang mempengaruhi orang tua kurang berperan adalah kebudayaan, pendidikan dan pekerjaannya. Peran orang tua kurang berperan ditunjukkan dengan kurangnya dalam berinteraksi dengan sekolah, memberikan wawasan tentang pelecehan seksual sejak dini, membiasakan anak untuk terbuka, dan menghindari bertengkar di depan anak. upaya meningkatkan kepedulian orang tua, diharapkan dapat mengurangi kasus pelecehan seksual pada anak usia sekolah.
\end{abstract}

Kata Kunci: Peran orang tua, pelecehan seksual 
Dewasa ini sering sekali terjadi pelecehan seksual oleh orang dewasa terhadap anak-anak. Anak-anak lebih menjadi sasaran orang dewasa karena anakanak dianggap sebagai makhluk yang polos. Kepolosan anak ini dimanfaatkan beberapa oknum untuk melakukan tindak asusila. Masa anak-anak adalah masa bermain dan berkarya, dimana mereka baru belajar dalam mengenal diri mereka sendiri serta mengenali orang lain selain kedua orang tua atau keluarganya sendiri. Tapi sangat disayangkan jika masa-masa itu harus ternoda karena tindakan kekerasan seksual yang mereka alami oleh orang yang tidak bertanggung jawab.

Menurut KP2A yang berdasarkan penuturan Yulis Has S.H,M.H (2015), menjelaskan bahwa ada beberapa peran bagi orang tua dalam menghindarkan anaknya dari pelecehan seksual, yaitu: mengawasi dan memperhatikan aktivitas anak sehari-hari (sekolah, teman bermain, dirumah, dan diluar rumah), menasehati anak untuk berpakaian, bersikap, berperilaku yang baik dan sopan, memberikan pendidikan agama sejak dini, menjadi figur yang dikagumi dan dibanggakan oleh anak-anaknya, menciptakan suasana yang kondusif dalam keluarga.

Pelecehan seksual adalah segala bentuk perlakuan seksual yang terjadi kepada seseorang, orang tersebut merasa tidak nyaman, perlakukan ini tidak diharapkan oleh korban pelecehan.

Pelecehan seksual digolongkan menjadi dua macam yaitu: pelecehan seksual tanpa sentuhan, yaitu (mengintip, lelucon-lelucon cabul, bicara kotor, melalui telepon atau secara langsung, siulan iseng dari seorang laki-laki ke perempuan yang tidak dikenalnya, memainkan mata kepada orang yang tidak dikenal; Pelecehan dengan sentuhan, yaitu: meraba-raba tubuh orang lain dengan sengaja, mencolek orang yang tidak dikenal dengan sengaja).

Betapa menderitanya orang yang pernah mengalami pelecehan seksual. Untuk orang yang pernah mengalami hal tersebut, tentu saja aktivitasnya tidak seleluasa biasanya. Dampaknya ialah sebagai berikut (dr. Soetjiningsih,1994:171): tanda akibat trauma atau infeksi lokal, misalnya nyeri perineal, sekret vagina,nyeri dan pendarahan anus, tanda gangguan emosi, misalnya konsentrasi berkurang, enuresis, enkopresis, anoreksia, atau perubahan tingkah laku, tingkah laku atau pengetahuan seksual anak yang tidak sesuai dengan umurnya.

Berdasarkan hasil studi pendahuluan yang dilakukan, data KP2A kota Blitar tentang kasus kekerasan pada anak di Kota Blitar tahun 2014, tercatat
73 kasus yaitu 20 kasus di kecamatan Kepanjenkidul, 24 kasus di kecamatan Sananwetan, dan 12 kasus di kecamatan Sukorejo. Dalam studi pendahuluan yang dilakukan oleh peneliti diketahui bahwa kecamatan Sanawetan memiliki jumlah kasus pelecehan seksual pada anak yang terbanyak.

Padahal sejatinya anak-anak memiliki hak Konstitusional mendapat perlindungan dari kekerasan seksual. Hak perlindungan anak tertuang dalam UU Nomor 23 tahun 2002 pasal 4, yaitu setiap anak berhak untuk dapat hidup, tumbuh, berkembang, dan berpartisipasi secara wajar sesuai dengan harkat dan martabat kemanusiaan serta mendapat perlindungan dari kekerasan dan diskriminasi. Dengan norma itu, pemerintah dipandang berkewajiban dan bertanggung jawab terhadap perlindungan anak dari kekerasan seksual.

Dari latar belakang tersebut diatas, peneliti tertarik untuk melakukan penelitian berkaitan dengan gambaran peran orang tua dalam melindungi anak usia sekolah dari tindakan kekerasan seksual di SDN Sananwetan 02 Kota Blitar.

\section{BAHAN DAN METODE}

Populasi dalam penelitian ini adalah orang tua yang memiliki siswa di Sekolah Dasar Negeri Sananwetan 02 Blitar Kota Blitar. Sampel yaitu orang tua yang memiliki anak yang bersekolah di SDN Sanawetan 02 Kota blitar yang berjumlah 58 orang. Teknik sampling yang digunakan adalah quota sampling, yaitu menentukan jumlah populasi sesuai kriteria yang sudah ditentukan.

Penelitian ini dilakukan di rumah-rumah orang tua yang berada di wilayah SDN Sananwetan 02 Kota blitar, Jln. Majapahit, Jln. Samosir, Jln. Natuna, Jln. Madura, Jln. Kangean, Jln. Emda Soepomo, Jln. Singo Dongso, dan Jln. Suryat. Penelitian dilaksanakan pada bulan Juli 2015. Penelitian ini menggunakan instrumen pengumpulan data berupa kuesioner yang dikembangkan peneliti berdasarkan peran orang tua dalam melindungi anak dari pelecehan seksual. Kuesioner terdiri dari data umum yang berjumlah 5 dan data khusus berjumlah 14 .

Data disajikan dalam bentuk tabel distribusi frekuensi dan dianalisa secara deskriptif.

\section{HASIL PENELITIAN}

Berikut ini akan disajikan data khusus mengenai gambaran peran orang tu dalam melindungi anak usia sekolah dari tindakan pelcehan seksual yang diukur dari kuesioner yang berjumlah 14 pernyataan. 
Tabel 1. Peran orang tua dalam melindungi anak usia sekolah dari tindakan pelecehan seksual di SDN Sananwetan 02 Kota Blitar Juli 2015

\begin{tabular}{cccc}
\hline \multirow{2}{*}{ No } & \multirow{2}{*}{ Kategori } & \multicolumn{2}{c}{ Peran Orang Tua } \\
\cline { 3 - 4 } & & F & \% \\
\hline 1 & San gat Berperan & 2 & $3 \%$ \\
2 & Cukup Berperan & 16 & $28 \%$ \\
3 & Kurang berperan & 40 & $69 \%$ \\
\hline & Total & $\mathbf{5 8}$ & $\mathbf{1 0 0 \%}$ \\
\hline
\end{tabular}

Berdasarkan tabel 1 bahwa 69\% (40 orang tua) kurang berperan, 28\% (16 orang tua) cukup berperan, $3 \%$ (2 orang tua) sangat berperan dalam melindungi anak usia sekolah dari tindakan pelecehan seksual.

\section{PEMBAHASAN}

Peran adalah seperangkat patokan, yang membatasi apa perilaku yang mesti dilakukan oleh seseorang yang menduduki suatu posisi (Suhardono, 1994). Peran orang tua dalam melindungi anak usia sekolah dari tindakan pelecehan seksual yaitu mengawasi dan memperhatikan aktivitas anak sehari-hari (sekolah, teman bermain, dirumah, dan diluar rumah), menasehati anak untuk berpakaian, bersikap, berperilaku yang baik dan sopan, memberikan pendidikan agama sejak dini, menjadi figur yang dikagumi dan dibanggakan oleh anak-anaknya, dan Menciptakan suasana yang kondusif dalam keluarga (Yulis Has S.H,M.H, 2015), dapat mencegah anak usia sekolah menjadi korban dari tindakan pelecehan seksual yang mengarah ke tindakan asusila. Peran orang tua dipengaruhi oleh beberapa faktor, menurut Mu'tadin (2002) yaitu, faktor budaya, faktor pendidikan, dan faktor pekerjaan.

Berdasarkan hasil penelitian menjelaskan bahwa $3 \%$ (2 orang tua) sangat berperan $28 \%$ (16 orang) cukup berperan, dan $69 \%$ (40 orang tua) kurang berperan dalam melindungi anak usia sekolah dari tindakan pelecehan seksual. 100\% (58 orang tua) bersuku jawa. Menurut Soetjiningsih (1995), adat istiadat yang berlaku di tiap daerah akan berpengaruh terhadap bagaimana orang tua mendidik anak. peneliti beranggapan bahwa mengajak anak bercerita tentang pelecehan seksual merupakan hal yang tabu untuk dibicarakan antara orang tua dan anak.

Berdasarkan tabulasi silang, 36\% (21 ayah) berpendidikan terakhir SMA dan 50\% (29 ibu) berpendidikan terakhir SMA. Pendidikan orang tua merupakan salah satu faktor yang mempengaruhi dalam memberikan pendidikan pada anak, karena tingginya jenjang pendidikan yang dimiliki oleh orang tua merupakan salah satu pendukung luasnya pengetahuan yang dimiliki orang tua (Mu'tadin, 2002). Menurut Notoadmodjo (2003), pendidikan mempengaruhi proses belajar, makin tinggi pendidikan seseorang makin mudah orang tersebut untuk menerima informasi. Dengan tingginya pendidikan maka orang tersebut semakin luas pengetahuannya. Peneliti beranggapan bahwa orang tua yang mempunyai pendidikan yang lebih tinggi serta yang berperan aktif dalam mencari informasi akan cenderung lebih aktif dalam mengkomunikasikan sesuatu yang diperlukan oleh anak usia sekolah, sehingga pengetahuan dan pemahaman orang tua dan anaknya tentang pelecehan seksual serta cara melindungi diri menjadi lebih baik.

Dari hasil tabulasi silang, 46\% (27 ayah) memiliki pekerjaan swasta dan 45\% (26 ibu) memiliki pekerjaan sebagai ibu rumah tangga. Menurut Friedman (1998) pekerjaan akan menyita waktu yang dapat digunakan seseorang. Sedangkan ibu rumah tangga memiliki waktu luang lebih atau kesempatan untuk memperhatikan anaknya serta mengikuti perkembangan anaknya. Peneliti beranggapan bahwa semakin sering orang tua berinteraksi dengan anaknya, peran orang tua dalam melindungi anak usia sekolah dari tindakan pelcehan seksual akan semakin meningkat.

Dari hasil tabulasi silang, data khusus nomer 8 menunjukkan $88 \%$ (48 orang tua) menjawab tidak dan $12 \%$ (7orang tua) menjawab iya dalam memberikan wawasan tentang pelecehan seksual pada anak usia sekolah sejak dini. Menurut Edward (2006), seringkali orang tua mengikuti cara-cara yang dilakukan oleh masyarakat dalam mendidik anak, kebiasaan-kebiasaan masyarakat disekitarnya dalam mendidik anak, karena pola-pola tersebut dianggap berhasil dalam mendidik anak kearah kematangan. Peneliti beranggapan bahwa orang tua mengharapkan anaknya dapat diterima di masyarakat dengan baik sehingga orang tua mendidik anaknya sesuai dengan suku yang dominan di masyarakat.

Dari hasil tabulasi silang, data khusus nomer 3 menunjukkan $93 \%$ (51 orang tua) menjawab tidak dan $7 \%$ (8 orang tua) menjawab iya dalam bekerja sama dengan guru untuk mengawasi anak di sekolah. Menurut BKKBN (2012) orang tua wajib mendampingi anak agar mereka tidak terjerumus ke dalam pergaulan yang membawanya ke dalam kenakalan anak dan tindakan yang merugikan 
dirinya sendiri. Peneliti beranggapan bahwa orang tua yang mendampingi anak dengan sikap bersahabat dapat membuat anak usia sekolah lebih merasa aman dan terlindungi dari tindakan pelecehan seksual.

Dari hasil tabulasi silang, data khusus pada nomer 14 didapatkan hasil $84 \%$ (49 orang tua) menjawab tidak dan $16 \%$ ( 9 orang tua) dalam menghindari pertengkaran di rumah di depan anaknya. Menurut (Yulis Has S.H,M.H, 2015), menjaga kondisi keluarga di dalam rumah untuk tetap nyaman dan harmonis merupakan salah satu peran orang tua dalam melindungi anak dari tindakan pelecehan seksual. Peneliti beranggapan bahwa semakin harmonis keadaan suatu keluarga meliputi saling menghargai, menyayangi, dan saling memberi perhatian kepada semua anggota keluarga khususnya bagi anak usia sekolah, karena akan membuat anak menjadi merasa nyaman di dalam rumah dan merasa aman di dalam rumah, sebaliknya jika di dalam keluarga hanya ada pertengkaran maka akan membuat anak tidak nyaman dan membuat anak cenderung mecari kenyaman di luar rumah.

Berdasarkan hasil tabulasi data umum, menunjukkan bahwa pekerjaan ayah dan ibu yaitu lainnya seperti sales dan buruh. Menurut Harno (2012) orang tua yang bekerja sebagian waktu dihabiskan diluar rumah untuk bekerja, hal ini mengurangi intensitas bertemu dan efisiensi waktu kebersamaan dengan anak. Peneliti berpendapat bahwa orang tua yang menghabiskan sebagian besar waktunya untuk bekerja memiliki kedekatan yang berbeda dengan orang tua yang bekerja tetapi sebagian waktunya masih diberikan untuk anak, sehingga orang tua kurang menyiapkan untuk melindungi anak usia sekolah dari tindakan pelecehan seksual.

\section{SIMPULAN DAN SARAN}

\section{Simpulan}

Berdasarkan hasil penelitian dan analisa data yang telah dilakukan dapat disimpulkan bahwa 69\% (40 orang tua) kurang berperan, $28 \%$ (16 orang tua) cukup berperan, $3 \%$ (2 orang tua) sangat berperan dalam melindungi anak usia sekolah dari tindakan pelecehan seksual. Orang tua kurang berperan ditunjukan dengan sekolah, memberikan wawasan tentang pelecehan seksual. Orang tua kurang berperan ditunjukan dengan kurang dalam berinterkasi dengan sekolah, memberikan wawasan tentang pelecehan seksual sejak dini, membiasakan anak untuk terbuka dalam keluarga, dan menghindari bertengkar di depan anak. Sedangkan orang tua yang sangat berperan ditunjukan denga selalu bertanya kepada anak tentang apa saja yang anak lakukan saat di sekolah, dan selalu banyak meluangkan waktu bersama anaknya.

\section{Saran}

Saran bagi orang tua harus selalu mengantarkan anaknya ke sekolah dan lebih sering meluangkan waktu bersama anaknya serta tidak bosan mencari banyak informasi tentang pelecehan seksual, bagi peneliti selanjutnya diharapkan penelitian ini dapat dikembangkan lebih jauh dengan permasalahan faktor-faktor yang mungkin berpengaruh pada peran orang tua dalam melindungi anak usia sekolah (612 tahun) dari tindakan pelecehan seksual selain faktor pendidikan, faktor budaya, dan faktor pekerjaan orang tua, bagi Komisi Perlindungan Anak Indonesia untuk segera melakukan sosialisasi tentang pelecehan seksual kepada orang tua dan menyiapkan hukuman yang tegas kepada para pelaku pelecehan seksual, serta KPAI harus membentuk organisasi tertentu dalam menanggani khusus di bidang pelecehan seksual, bagi institusi pendidikan keperawatan hasil penelitian ini dapat dijadikan sebagai bahan masukan dalam pengembangan konsep ilmu keperawatan.

\section{DAFTAR RUJUKAN}

Alimul, Aziz. 2003. Riset Keperawatan \& Teknik Penulisan Ilmiah. Jakarta: Salemba Medika.

Arikunto, Suharsimi. 2006. Prosedur Penlitian Suatu Prndekatan Praktek. Jakarta: Rineka Cipta.

Efendi, Ferry. 2009. Keperawatan Komunitas: Teori dan Praktik dalam Keperawatan. Jakarta: Salemba Medika.

Friedman, Marilyn. 1998. Keperawatan Keluarga: Teori dan Praktik. Jakarta: EGC.

Gunarsa, Singgih D. 2008. Psikologi Praktis: Anak, Remaja dan Keluarga. Jakarta: Gunung Mulia.

Notoatmodjo, Soekidjo. 2010. Metodologi Penelitian Kesehatan. Jakarta: Rineka Cipta.

Suhardono, Edy. 1994. Teori Peran: Konsep Derivasi dan Implikasi. Jakarta: Gramedia Pustaka Utama.

Soetjiningsih. 1995. Tumbuh Kembang Anak. Jakarta: EGC.

Wong, Donna L. 2008. Buku Ajar Keperawatan Pediatrik. Jakarta: EGC.

Cahyaningsih, D.S. 2011. Pertumbuhan Perkembangan Anak dan Remaja. Jakarta: CV. Trans Info Media.

Nursalam. 2008. Konsep dan Penerapan Metodologi Penelitian Ilmu Keperawatan. Surabaya: Salemba Medika. 
Notoatmodjo, Soekidjo. 2002. Promosi Kesehatan. Jakarta: Rineka Cipta.

Irwansyah \& Asep K.N. 2006. Sehat dan Tangkas Berolahraga. Jakarta: Grafindo Media Pratama.

Abu Huraerah. 2006. Kekerasan Terhadap Anak. Jakarta: Penerbit Nuansa.

Emmy, Soekresno S. 2007. Mengenali Dan Mencegah Terjadinya Tindak Kekerasan Terhadap Anak. Jakarta: Nuasa Media.

Mafrukhi. 2006. Kompeten Berbahasa Indonesia. Jakarta: Penerbit Erlangga.
Huraerah, Abu. 2006. Kekerasan Terhadap Anak Jakarta: Penerbit Nuansa.

Kartono, Kartini. 2005. Patologi Sosial 2, Kenakalan Remaja, cet ke-2. Yogyakarta: PT Gloria Usaha Media.

Stewart, E.D., dkk. 1992. Pelecehan Seksual. Jakarta: Rajawali.

Chomaria, Nurul. 2008. Aku Sudah Gede. Solo: Samudera Azwar, Saifuddin. 1998. Sikap Manusia: Teori dan Pengukurannya. Yogyakarta: Pustaka Pelajar. 